This item was submitted to Loughborough's Research Repository by the author.

Items in Figshare are protected by copyright, with all rights reserved, unless otherwise indicated.

\title{
Surveillance and identity management: migrant perspectives on UK Biometric Residence Permits
}

PLEASE CITE THE PUBLISHED VERSION

http://dx.doi.org/10.1016/j.clsr.2011.03.004

\section{PUBLISHER}

Elsevier (@) The authors)

VERSION

AM (Accepted Manuscript)

LICENCE

CC BY-NC-ND 4.0

\section{REPOSITORY RECORD}

Warren, Adam P., and Elizabeth Mavroudi. 2019. "Surveillance and Identity Management: Migrant Perspectives on UK Biometric Residence Permits”. figshare. https://hdl.handle.net/2134/8429. 
This item was submitted to Loughborough's Institutional Repository (https://dspace.lboro.ac.uk/) by the author and is made available under the following Creative Commons Licence conditions.

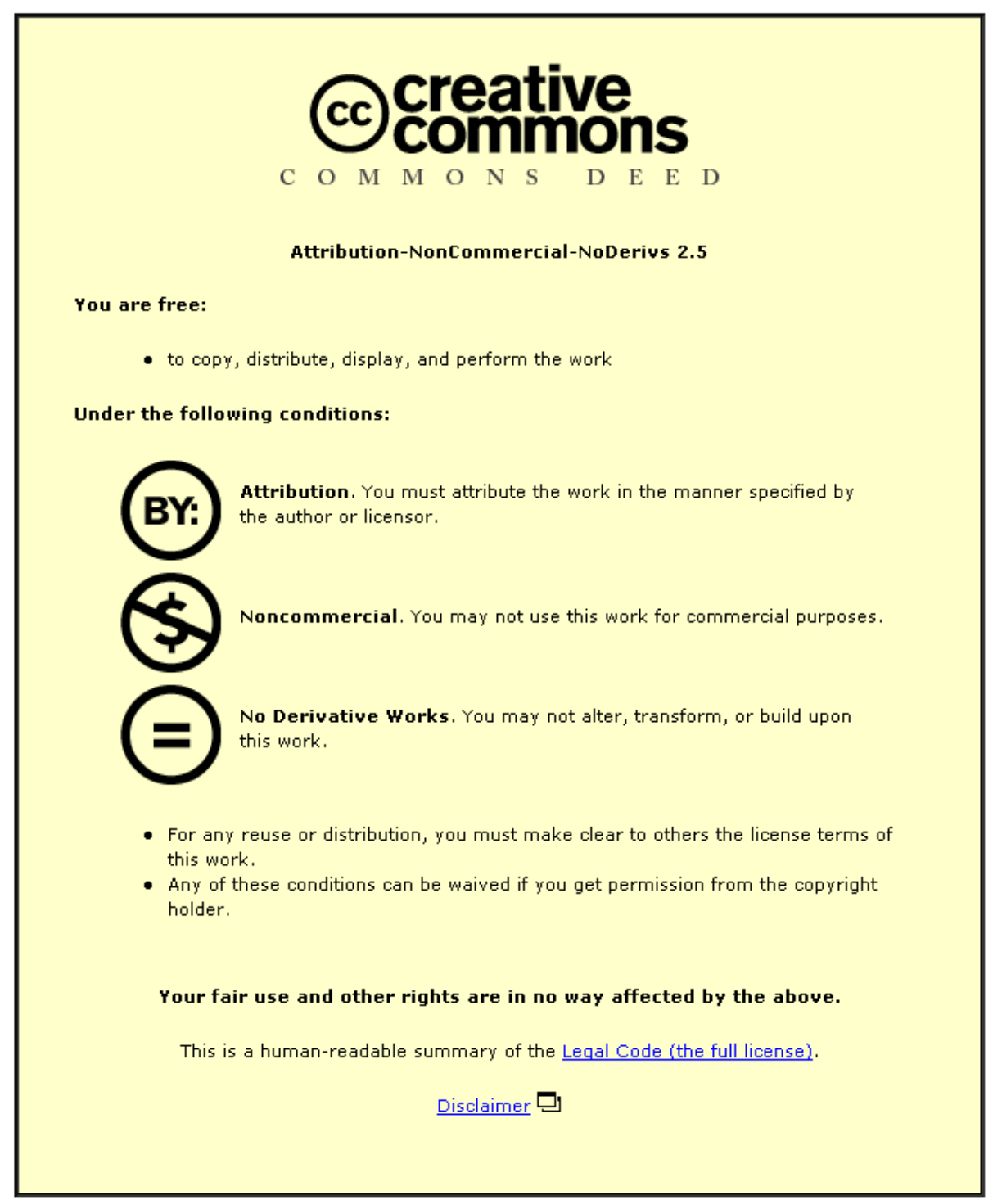

For the full text of this licence, please go to: http://creativecommons.org/licenses/by-nc-nd/2.5/ 


\section{Surveillance and Identity Management: Migrant perspectives on UK Biometric Residence Permits}

\section{Dr Adam Warren (a.p.warren@lboro.ac.uk); Dr Liz Mavroudi (e.mavroudi@lboro.ac.uk)}

Department of Geography, Loughborough University, UK.

\section{Introduction}

It is over two years since the first national identity cards for more than half a century were issued by the UK government. On 25 November 2008, the Labour administration began the roll-out of identity cards to 'foreign nationals', a term used to refer to diverse non-EEA migrants including visiting scholars, entrepreneurs, professionals, investors and domestic workers. Although the new Conservative-Liberal Democrat Coalition government, formed following the May 2010 general election, has repealed the identity card scheme for UK citizens, it will remain in place for an expanding number of foreign national groups. By November 2010, over 300,000 cards - now known as 'Biometric Residence Permits' (BRPs) - had been issued to foreign nationals (HoL, 2010). The continued roll-out of BRPs to specific groups of UK residents as part of the Points Based System (PBS) raises a number of policy issues, particularly in relation to the 'management' of migration through greater surveillance and governance of personal data through personal identity management. In this paper, we draw on findings from our own empirical work, to shed light on these issues. Our research - conducted between March and December 2010 - involved in-depth interviews with policymakers, advocacy groups, Higher Education (HE) administrators and 25 foreign nationals, either employed or studying in the HE sector. We conclude by arguing that policy in this area can be improved by paying greater attention to the perspectives of foreign nationals using BRPs.

\section{Biometric Residence Permits: the enrolment process}

BRPs are currently being phased in across a number of foreign national classifications, with students, domestic workers, skilled workers with a job offer and entrepreneurs among those required to obtain the permit. Enrolment involves the digital recording of facial images of all affected migrants and the scanning of 10 digit fingerprints of applicants aged over six. Recording can be done at UK Border Agency (UKBA) biometric enrolment centres (for postal applications), UKBA public enquiry offices (for in-person applications) or via designated post offices. Costs of enrolment are included as part of the visa application procedure and vary from $£ 120$ for a temporary worker permit acquired via the post to $£ 1,150$ for a highly skilled worker visa applied for in-person ${ }^{1}$. Postal applications take approximately four to eight weeks ${ }^{2}$, whilst in-person, or 'premium', submissions are processed either on the same day, or within 24 hours. Once captured, the information is - in most cases - retained indefinitely, including after the departure of an applicant from the $\mathrm{UK}^{3}$.

As part of our empirical research, we were given walk-through tours by UKBA management of two public enquiry offices (PEOs), situated in two large English cities. During these visits, we witnessed the capture of biometric data, and its subsequent verification and checking against police and immigration databases (such as the National Fingerprint Database, IDENT1 $1^{4}$ ), by UKBA officials. According to one UKBA employee, the biometric data is stored 'in a secure area on an existing database' (see also Mercer, 2009). In almost all cases, it is retained indefinitely, including after the foreign national returns to their home country. At a large PEO, the authentication process can take between 30 minutes and three hours. The applicant will be required to wait whilst these checks are being made. Once the results are known, the individual will be informed and either allowed to leave (if a postal application) or be referred to a caseworker (if an in-person application). The enrolment information - for both postal and in-person applications - is then transferred to a casework team, which will make a final decision. If the BRP is granted, the applicant's biometric data is sent in encrypted form to the Driver and Vehicle Licensing Agency in Swansea, where it is then decrypted and run for card production. It is intended that the card will be received by the applicant within 10 working days of the date of the decision letter.

\footnotetext{
${ }^{1}$ Refer: http://www.ukba.homeoffice.gov.uk/contact/applyinginperson/cost/\# [accessed 06.01.11].

${ }^{2}$ Interviewee, UKBA, October 2010.

${ }^{3}$ Interviewee, UKBA Public Enquiry Office (PEO), September 2010. However, other interviewees at this PEO appeared uncertain in relation to this matter.

${ }^{4}$ Refer: http://www.npia.police.uk/en/10504.htm [accessed 06.01.11].
} 


\section{Preliminary Findings}

The data collected during our empirical research has been rich and varied. In this section, we wish to draw attention to some interviewee - in particular, migrant - perceptions of the BRP. Although the sample is relatively small, it has been possible to identify some general trends. Firstly, whilst HEI administrators and the advocacy groups contacted did highlight the utility of the BRP and the accompanying PBS as mechanisms for placing certain migrant groups under greater surveillance, this was barely mentioned by foreign nationals interviewed. Even when prompted, most interviewees stated that they did not consider themselves to be under surveillance. However, they did not express concerns at the way in which the scheme was being applied solely to non-EEA nationals. Secondly, the acquisition of BRPs appeared to have had little impact on how individual foreign nationals managed their personal identity as they went about their everyday lives. In fact, many interviewees, having enrolled for the card, seemed uncertain as to its purpose. Nevertheless, applicants on the whole appeared to trust the UK government with the management of their biometric data. This is in contrast with privacy and security concerns raised by advocacy groups, as well as by a number of academic researchers and journalists. We will now examine these two trends in a little more detail.

\subsection{A surveillance tool?}

Undoubtedly, the BRP - agreed in principal at EU level - was introduced by the UK and other member state governments to monitor migration into sovereign territory. Indeed, one of the purported advantages of a biometric identifier of this nature was that it would 'securely lock [foreign nationals] into one identity' (Wired-gov.net, WWW). Moreover, within the HE sector, the application of the PBS to overseas students has resulted in a series reporting duties being imposed on all HEIs. For example, if a student misses ten 'expected interactions' (such as attendance of lectures, seminars, tutorials and submission of coursework), the HEI is obliged to notify the UKBA (UKBA, 2010). As non-compliance could result in loss of the HEI's right to recruit high fee paying non-EEA students, HEI administrators interviewed found this process to be burdensome, and a little stressful. The advocacy groups participating in our study were more scathing of the BRPs, defining them as 'a control mechanism' which enabled certain groups of migrants to 'be grabbed hold of pretty quickly if they stepped out of line’ (Manager, national migrant advocacy group).

Nevertheless, the majority of foreign nationals interviewed raised few objections to enrolment of their biometric data as part of the process of applying to work or study in the UK. Many came from countries with similar identity card systems in place, and participants were in general reluctant to perceive the requirement of BRPs in terms of surveillance. In the words of one migrant, employed as an academic, 'I can do what I want as long as it's not illegal'. This perspective may be grounded in the fact that, with the exceptions of registration with their HEI and entry into the UK via border control, interviewees were not usually called on to produce their BRPs as they went about their daily lives. The main objection to the BRP amongst cardholders, therefore, arose from its coverage of a specific sector of the UK population. The use of surveillance tools to categorise, or 'sort', certain demographic groups, especially in relation to managing migration, has been extensively critiqued by scholars (see, for example: Lyon, 2007a, 2007b; Bosworth, 2008; Hampshire, 2009). Our preliminary findings lend some support these perspectives, in particular to Lyon's contention that 'new' biometric identity card systems facilitate the 'sorting of 'desirable' and 'undesirable' mobilities, based on the criteria of 'identity management" (2007b: 111). This is evidenced in the excerpts from our fieldwork interviews, given below:

'I don't mind ID cards as such, but I do mind that it's only the foreign nationals which are going to go through it' (HEI student)

'It will make me feel all the more alienated if anything else, I mean, why would you want to stigmatise people in this way?' (HEI staff)

'Why should it only be non-EEA people who get singled out? [...] I think it's because I don't class myself as being different from anyone next to me, it [is] more or less pointed out you're different; you're not from here.' (HEI staff) 
Interviewees were concerned that the designation of an identity card in this way could result in stigmatisation, particularly if providers of goods and services such supermarkets, banks, car hire companies and landlords began to demand its production as a matter of course. Some interviewees, reporting existing personal experiences of discriminatory treatment (especially in relation to job applications), saw the roll-out of an identity card solely for foreign nationals as potentially exacerbating this behaviour. More than one interviewee had noticed that, in the words of one foreign national employed as a lecturer, the 'social climate' in the UK had 'changed'. In part, this was due the discourse of certain national newspapers, which in the words of another foreign national academic, 'publish[ed] regularly articles which are absolutely wrong'. This appeared to 'steer' attitudes within the communities in which they lived:

'.. you do feel a bit less welcome when you go to the local shops and for doing your normal things, I have found. I have felt that over the last 3 months. And having an ID card wouldn't help at all...' (HEI staff)

\subsection{Personal Identity Management}

According to Beynon-Davies (2006), in his case study on the proposed UK national identity card as a token of citizenship ${ }^{5}$, personal identity management comprises three processes, posing three distinct questions: authentication ('am I who I claim to be?'); identification ('who am I?); and enrolment ('what am I expected to do and to receive?'). To a large extent, the concerns and suspicions about the introduction of a BRP for a section of the population were a response Beynon-Davies' third question. Participants were unsure of the purpose of the BRP, its benefits and of what exactly it was replacing. There was uncertainty as to whether it could be used as a passport or to guard against, in the words of one student, 'random checking', 'for example, when driving and there is a police officer'. At the same time, interviewees gave examples of when the BRPs had failed to address Beynon-Davies' second question on identification. One student reported that his card was not recognised when he was asked to provide proof of identity to buy alcohol at the local supermarket; another interviewee stated that his permit had caused the authorities some confusion when he displayed it to border officials in another EU country. Indeed, for some interviewees, the BRP only succeeded in addressing the first identity management process (authentication) at certain points during their study or employment at UK HEIs.

Yet, in spite of these problems, interviewees expressed confidence in the ability of the UK government to manage their personal information. This is in contrast with recent academic research. For instance, Raab et al highlighted concerns at the propensity of the UK government to resort to database 'solutions' to social or policy problems, which, in turn, 'require large amounts of personal data' to identify and profile individuals (2010: n.p.). Anderson et al, in a study commissioned by the Joseph Rowntree Reform Trust, declared that at least 10 UK government databases were 'almost certainly illegal under human rights or data protection law' (2009: 5). The findings of the latter report - albeit authored by some eminent scholars - were controversial and have been disputed by the UK government (Ministry of Justice, 2009). Nevertheless, a number of data breaches, culminating in the loss of 25 million child benefit records by the HMRC in 2007, resulted in government systems being placed under greater scrutiny (Wintour, 2007; Cabinet Office, 2008). However, our findings show that these incidents did not necessarily register with interviewees. Only one participant, a manager employed by a migrants' rights advocacy group, referred to previous government data handling scandals. Indeed, foreign national students appeared to be more suspicious of private sector organisations, in particular, financial institutions, where a greater imperative may exist to exploit personal information for commercial gain. Thus, although a non-EEA student voiced concern that their biometric data could be targeted by hackers, other interviewees commented on government's ostensible accountability:

'I’m happy to trust the government because simply if something goes wrong, then I can shout; there will be people to hear' (HEI staff)

In summary, the prevailing view among interviewees on this matter was perhaps best expressed by another HEI employee:

\footnotetext{
${ }^{5}$ During the debate on the introduction of a UK-wide national identity card, possession was viewed as evidence of citizenship 'which, in turn, will confer a range of rights and obligations on the individual' such as rights to healthcare and obligations to pay tax (Beynon-Davies, 2006: 11).
} 
'... as long as you can have a good protection of the data, then I think there's no harm in having a biometric ID card...'

\section{Discussion and Conclusion}

The aim of this paper was to highlight areas for further policy debate within the broad fields of migration management and the governance of personal data. The introduction of BRPs for UK foreign nationals was used as a case study. This is a wide-ranging topic, and there are matters that we have not addressed, including, notably, the forthcoming cap on non-EEA migration to UK. In addition, a more in-depth study of the surveillance potential of the BRPs would investigate the security of using an existing government database to store biometric data (Lyon, 2007b). Finally, this brief article has largely focused on one perspective (albeit one that is sometimes not given due prominence), that of the migrant. The voices of advocacy groups, legal and technology experts and legislators also need to be heard, and scrutinised.

Nevertheless, our study does raise some important points. Whilst individual migrants generally expressed trust in the ability of UK government agencies to handle their personal data appropriately, there was some concern about the vulnerability of this data to attack by hackers. With the capture and processing of biometric data such as fingerprints and facial images by national governments becoming increasingly common (Grijpink, 2009; Aquilina, 2010), there is a need for UK government agencies, in particular, to maintain these levels of confidence, ensuring that robust and clearly accountable data handling procedures are in place. In many respects, this is a matter of 'governance', a term with a variety of meanings (Stoker, 2003), but which generally refers to series of dynamic processes of governing, with the state increasingly perceived as facilitator, rather than controller, of services (Newman, 2001). Developing citizen trust in the activities of state is central to this changed style of service provision. However, this has proved a longstanding challenge for public policymakers (Parry, 1976; Bloomfield et al, 2001; Bouckaert and van de Walle, 2003).

Our findings to date indicate that trust does exist among UK foreign nationals. Nevertheless, it is important that policymakers actively seek to maintain it. We suggest that this can be achieved through improved communication, greater transparency and stronger accountability. For instance, further work is required to inform foreign nationals of: the purpose of the BRP; the necessity of holding the data collected at enrolment; and the rationale for holding such data 'indefinitely' in most cases. Given that interviewees did not object in principle to providing their biometric data to the UK government as part of the visa enrolment process, it is incumbent on policymakers to ensure that these procedures impose fewer burdens (without comprising security) on applicants and are less subject to change at short notice

Greater transparency involves ensuring that applicants are informed about, and understand, what happens to their personal data after it is collected - rather than being given general assurances that it will be processed in accordance with the Data Protection Act 1998 (and other relevant legislation). Personal data must accurate and kept up to date, and appropriate measures should be taken to ensure it is securely held (Beynon-Davies, 2006). Moreover, in order to maintain quality systems, it is vital that the requirement for annual compliance checks with data protection and risk management procedures, set out in the government's Data Handling Review (Cabinet Office, 2008: 7ff), are enacted. A summary report of the compliance checks should be published. These measures, whilst not exhaustive, will help policymakers implement one of the key components of twenty-first century governance: effective service delivery (Sims, 2001; Taylor et al, 2008). Finally, stronger accountability demands that applicants have direct recourse to complaint-handling procedures should they not be satisfied with the way in which their application has been processed.

The foreign nationals interviewed during our research were highly educated, skilled individuals who had elected to study or work in the UK. They contribute greatly to UK Plc, with international students and visitors estimated to be generating $£ 2.4$ billion for the national economy through off-campus expenditure alone (Universities UK, 2009; see also Home Office, 2008). Our preliminary work in this area suggests that policymakers, in addition to ensuring that recent reforms do indeed preserve confidence in the UK government's data handling processes, need to take greater account of foreign national perceptions of living within the UK. In particular, attention should be paid to the perceived unfairness of the BRPs and their potential, by virtue of being targeted at specific groups, to stigmatise foreign nationals. Whilst most interviewees had a positive view of life in the UK, some had experienced discrimination and others remarked on the 'changed' attitudes towards migrants with rhetoric, in certain media outlets and in specific localities, 
becoming more hostile. If the UK is to continue to benefit - economically, socially and culturally - from the presence of these skilled migrants, then policymakers need to respond to the concerns raised in this paper.

\section{References}

Anderson, R., Brown, I., Dowty, T., Inglesant, P., Heath, W. and Sasse, A. Database State, York: Joseph Rowntree Reform Trust; 2009.

Aquilina, K. Public security versus privacy in technology law: A balancing act? Computer Law and Security Report, 2010, 26(2): 130-143.

Beynon-Davies, P. Personal identity management in the information polity: the case of the UK national identity card, Information Polity, 2006, 11(1): 3-19.

Bloomfield, D., Collins, K., Fry, C. and Munton, R. Deliberation and inclusion: vehicles for increasing trust in UK public governance? Environment and Planning C: Government and Policy, 2001, 19(4): 501-513.

Bosworth, M. Border control and the limits of the sovereign state, Social and Legal Studies, 2008; 17(2): 199-215.

Bouckaert, G. and van de Walle, S. Comparing Measures of Citizen Trust and User Satisfaction as Indicators of 'Good Governance': Difficulties in Linking Trust and Satisfaction Indicators. International Review of Administrative Sciences, 2003, 69(3): 329-343.

Cabinet Office. Data Handling Procedures in Government: final report. London: Cabinet Office; June 2008.

Grijpink, J. Trend report on biometrics: Some new insights, experiences and developments, Computer Law and Security Report, 2008; 24(3): 261-264.

Hampshire, J. The future of border control: risk management of migration in the UK in Fassmann, H., Haller, M. and Lane, D. (eds) Migration and Mobility in Europe. Cheltenham, Glos: Edward Elgar Publishing Ltd; 2009; pp. 229-248.

Home Office. The Economic Impact of Immigration. The Government reply to the First Report from the House of Lords Committee on Economic Affairs. Session 2007-08. HL Paper 82, Cm 7414, London: The Stationery Office; <http://www.official-documents.gov.uk/document/cm74/7414/7414.pdf $>$, June 2008 [accessed 06.01.11].

House of Lords (HoL). Debate, 8 November 2010. Hansard. http://www.publications.parliament.uk/pa/ld201011/ldhansrd/text/101108-gc0001.htm [accessed 06.01.11].

Lyon, D. Surveillance, security and social sorting: emerging research priorities, International Criminal Justice Review, 2007a; 17(30): 161-170.

Lyon, D. National ID Cards: Crime-Control, Citizenship and Social Sorting, Policing: A Journal of Policy and Practice, 2007b; 1(1), 111-118.

Mercer, T. Using biometrics to help secure UK borders. Biometric Technology Today, May 2009, 17(5): 7-8.

Ministry of Justice. Government response to the Joseph Rowntree Reform Trust report: 'Database state'. London: Ministry of Justice; 2009.

Newman, J. Modernising Governance. London: SAGE Publications Ltd; 2001.

Parry, G. Trust, Distrust and Consensus’. British Journal of Political Science, 1976; 6(2): 129-43. 
Raab, C., Ball, K., Graham, S., Lyon, D., Murakami Wood, D. and Norris, C. The surveillance society: An update report on developments since the 2006 Report on the Surveillance Society by members of the Surveillance Studies Network. Wilmslow: Information Commissioner’s Office; 2010.

Wintour, P. Information chief calls for review of ID card plans, The Guardian, $<$ http://www.guardian.co.uk/uk/2007/dec/05/idcards.humanrights?INTCMP=SRCH>; 5 December 2007 [accessed 06.01.11].

Wired.gov. Home Office News Release (055/2009) issued by COI News Distribution Service on 31 March 2009. Tough new rules target bogus colleges and education cheats $<$ http://www.wired-gov.net/wg/wg-news1.nsf/0/D1F4BACDD02AE69A8025758A00308612?OpenDocument> $>$, [accessed 06.01.11].

UK Border Agency (UKBA). Tier 4 Sponsor Guidance. London: UKBA; $<$ http://www.ukba.homeoffice.gov.uk/sitecontent/documents/employersandsponsors/pbsguidance/guidancefr om31mar09/sponsor-app-guidance-t4.pdf?view=Binary $>$, October 2010, [accessed 06.01.11].

Universities UK. The impact of universities on the UK economy: summary. London: Universities UK, $<$ http://www.universitiesuk.ac.uk/Publications/Documents/EconomicImpact4Summary.pdf >; $\quad$ November 2009 [accessed 06.01.11]. 